\title{
Association study between polymorphisms of CD28, CTLA4 and $I C O S$ and non-segmental vitiligo in a Korean population
}

\author{
MIN KYUNG SHIN ${ }^{1 *}$, SO HEE IM ${ }^{2 *}$, HAE JEONG PARK $^{3}$, SU KANG KIM ${ }^{3}$, \\ SUNG VIN YIM ${ }^{2}$, JOO-HO CHUNG ${ }^{3}$ and MU-HYOUNG LEE ${ }^{1}$ \\ Departments of ${ }^{1}$ Dermatology, ${ }^{2}$ Clinical Pharmacology, and ${ }^{3}$ Kohwang Medical Research Institute, \\ School of Medicine, Kyung Hee University, Seoul, Republic of Korea
}

Received July 7, 2011; Accepted July 25, 2011

DOI: $10.3892 /$ etm.2011.326

\begin{abstract}
CD28 molecule (CD28), cytotoxic T-lymphocyteassociated protein 4 (CTLA4) and inducible T-cell co-stimulator (ICOS) are important regulators of the immune system. Vitiligo, a common autoimmune skin disorder, is characterized by a loss of melanocytes that results in cutaneous white patches. The aim of the present study was to determine whether or not polymorphisms of the CD28, CTLA4 and ICOS genes are associated with non-segmental vitiligo in a Korean population. To determine the relationships between $C D 28$, CTLA4 and ICOS genes and vitiligo, four single nucleotide polymorphisms (SNPs) associated with the CD28 gene [rs1879877 (promoter, -1198), rs3181097 (promoter, -1059), rs2140148 (intron 1) and rs3116494 (intron 2)], two SNPs associated with the CTLA4 gene [rs231777 (intron 1) and rs231779 (intron 1)] and five SNPs associated with the ICOS gene [rs4270326 (intron 3), rs11571314 (intron 3), rs10183087 (3' untranslated region; UTR), rs4404254 (3'UTR) and rs1559931 (3'UTR)] were selected. Two hundred and thirty-one patients with non-segmental vitiligo (NSV) and 405 healthy controls were enrolled. Genotyping was performed using the restriction fragment length polymorphism technique and direct sequencing. SNPStats, Haploview 4.2 and SPSS 18.0 were used to conduct the analyses. Significant differences were noted between CTLA4 $(\mathrm{p}<0.05)$ and NSV, but not CD28 and $\operatorname{ICOS}(\mathrm{p}>0.05)$. However, these associations disappeared after Bonferroni correction. The CD28, CTLA4 and ICOS genes may not be associated with NSV.
\end{abstract}

Correspondence to: Dr Mu-Hyoung Lee, Department of Dermatology, School of Medicine, Kyung Hee University, 1 Hoegi-dong, Dongdaemun-gu, Seoul 130-702, Republic of Korea

E-mail:mhlee@khmc.or.kr

${ }^{*}$ Contributed equally

Key words: CD28 molecule, cytotoxic T-lymphocyte-associated protein 4 , inducible T-cell co-stimulator, non-segmental vitiligo, single nucleotide polymorphism

\section{Introduction}

Vitiligo is an acquired autoimmune skin disorder that is characterized by a loss of epidermal melanocytes (1). The prevalence of vitiligo is approximately $1 \%$ in the US and $0.1-2 \%$ worldwide (1). Vitiligo usually occurs in childhood or young adulthood, with a peak onset between 10 and 30 years of age (1). The pathogenesis of vitiligo is not completely understood. CD28 molecule(CD28), cytotoxic T-lymphocyte-associated protein 4 (CTLA4) and inducible T-cell co-stimulator (ICOS) are important regulators of the immune system. The $C D 28$, CTLA4 and ICOS genes lie in a $300-\mathrm{kb}$ region on chromosome 2 q33 (2). CD28 is a cell surface molecule present on most peripheral T-cells (2). CD28 provides co-stimulatory signals to T-cells that prevent the induction of cell death, and promotes interleukin 2 production and clonal expansion (3). CTLA4 is a member of the immunoglobulin superfamily and is a co-stimulatory molecule expressed by activated T-cells (4). CTLA4 transmits an inhibitory signal to T-cells, whereas CD28 transmits a stimulatory signal (4). ICOS is a receptor belonging to the same family as CD28 and CTLA4, known to regulate T-lymphocyte activation in immune responses. ICOS and CD28 enhance T-cell function for effective antigenspecific immune responses, whereas CTLA4 counterbalances CD28-mediated signals and thus prevents overstimulation of the lymphoid system (5). CTLA4 is associated with several autoimmune diseases, including autoimmune thyroid disease, Graves' disease and Hashimoto's thyroiditis (6). The $C D 28$, CTLA4 and ICOS genes, which are involved in T-cell regulation, may be candidate genes in autoimmune diseases.

In this study, we determined whether or not single nucleotide polymorphisms (SNPs) in the CD28, CTLA4 and ICOS genes are associated with increased susceptibility to nonsegmental vitiligo (NSV) in a Korean population.

\section{Materials and methods}

Patients and controls. Patients with NSV were recruited among dermatologic outpatients seeking treatment at the Kyung Hee University Medical Center in Seoul, Republic of Korea. Two hundred and thirty-one NSV patients [95 males and 136 females; mean age \pm standard deviation (SD), $38.7 \pm 18.2$ years] and 405 healthy controls (171 males and 234 females; mean age \pm SD, 
Table I. Clinical characteristics of the NSV patients and control subjects.

\begin{tabular}{lcc}
\hline & NSV & Controls \\
\hline Male/female, $\mathrm{n}$ & $95 / 136$ & $171 / 234$ \\
Age (mean age \pm SD, years) & $38.7 \pm 18.2$ & $39.2 \pm 9.8$ \\
Onset age, $\mathrm{n}$ & & \\
Childhood ( $\leq 18$ years) & 80 & \\
$\quad$ Adulthood (>18 years) & 151 & \\
Autoimmune diseases, $\mathrm{n}$ & & \\
$\quad$ With & 6 & \\
$\quad$ Without & 225 & \\
Family history, $\mathrm{n}$ & & \\
$\quad$ With & 29 & \\
$\quad$ Without & 202 & \\
\hline
\end{tabular}

NSV, non-segmental vitiligo.

$39.2 \pm 9.8$ years) were enrolled in the present study (Table I). NSV is an acquired chronic pigmentation disorder characterized by white patches, often with a symmetric distribution, which usually increases in size over time (1). The NSV patients were stratified into three groups according to the following clinical characteristics: i) child (age $\leq 18$ years) and adult onset (age $>18$ years); ii) association with other autoimmune diseases; and iii) family history (parents, sons, daughters, brothers and sisters) of vitiligo. The control subjects were recruited among participants in a general health check-up program after confirming that they had no clinical evidence of vitiligo or any other diseases. The Institutional Review Board of Kyunghee University Hospital approved the present study, and all participants provided written informed consent.

SNP selection and genotyping. We selected 11 SNPs within the CD28,CTLA4 and ICOS genes, and determined whether or not these SNPs were associated with vitiligo. Four SNPs of the CD28 gene [rs1879877 (promoter, -1198), rs3181097 (promoter, -1059), rs2140148 (intron 1) and rs3116494 (intron 2)], two SNPs of the CTLA4 gene [rs231777 (intron 1) and rs231779 (intron 1)] and five SNPs of the ICOS gene [rs4270326 (intron 3), rs11571314 (intron 3), rs10183087 (3' untranslated region; UTR), rs4404254 (3'UTR) and rs1559931 (3'UTR)] were selected based on data gathered from public SNP databases (http://www.ncbi.nlm.nih.gov/SNP/ and http://hapmap. ncbi.nlm.nih.gov) and previous studies (7-9). Coding SNPs of the CD28, CTLA4 and ICOS genes with heterozygosities $<0.1$ were excluded (CD28 gene, rs41272649, rs35290181 and rs75899942; CTLA4 gene, rs16840275; and ICOS gene, rs76778263). Other coding SNPs of the CD28, CTLA4 and ICOS genes were also excluded because of non-detected heterozygosity.

Genomic DNA was prepared from peripheral blood using a genomic DNA isolation kit (Roche, Indianapolis, IN, USA). The Roche DNA Extraction kit simplifies isolation of DNA from blood with a fast spin-column. DNA binds specifically to the Roche silica-gel membrane, while contaminants pass through. The DNA was stored at $-20^{\circ} \mathrm{C}$ for further study.
Genotypes of CD28, CTLA4 and ICOS SNPs were determined using a restriction fragment length polymorphism (RFLP) technique and direct sequencing analyses.

Statistical analysis. Chi-square tests were used to assess Hardy-Weinberg equilibrium (HWE). Genetic data were analyzed using SNPStats (http://bioinfo.iconcologia.net/ index.php?module=Snpstats), Helixtree (Golden Helix Inc., Bozeman, MT, USA), SNPAnalyzer (Istech Inc., Goyang, Korea) and SPSS 18.0 (SPSS Inc., Chicago, IL, USA). Calculation of linkage disequilibrium (LD) among the CD28, CTLA4 and ICOS polymorphisms was performed using Haploview 4.2. Haplotypes of LD were determined by the Gabriel method (10). Multiple logistic regression models (co-dominant, dominant and recessive models) were used to determine the odds ratio (OR), 95\% confidence interval (CI) and p-value, controlling for age and gender as co-variables $(11,12)$. The significance level was set at 0.05 .

\section{Results}

Clinical characteristics of the NSV patients. Eighty and 151 patients had child and adult onset NSV, respectively. Six patients had other autoimmune diseases and 225 patients had no other autoimmune diseases. Twenty-nine patients had family histories of NSV and 202 patients had no family histories of NSV (Table I).

Association study between polymorphisms of CD28, CTLA4 and ICOS and NSV in a Korean population. We investigated whether CD28, CTLA4 and ICOS polymorphisms are asssociated with NSV in a sample of Korean patients and controls. No significant deviations from HWE were detected for $C D 28$, CTLA4 and ICOS polymorphisms in the control group (data not shown). The genotype frequencies of CD28, CTLA4 and ICOS polymorphisms in NSV patients were compared to those of healthy control subjects by logistic regression models. Multiple logistic regression analyses were performed, while controlling for age and gender as co-variables in three models (co-dominant, dominant and recessive models).

The allele and genotype frequencies of CD28, CTLA4 and ICOS polymorphisms are shown in Tables II and III. The allele and genotype frequencies of the $C D 28$ and ICOS polymorphisms in the NSV patients were similar to the control subjects. However, the allele frequencies of the CTLA4 polymorphism (rs231777) were shown to differ between the NSV patients and the control subjects ( $\mathrm{p}=0.041, \mathrm{OR}=1.40,95 \%$ CI 1.01-1.94). The $\mathrm{T}$ allele frequency of rs 231777 was shown to have a higher rate in the NSV patients than in the control subjects (16.2 vs. 12.1\%) (Table II). However, there was no significant difference after Bonferroni correction. The genotype frequencies of the CTLA4 polymorphisms (rs231777 and rs231779) were also shown to be associated with NSV [rs231777, $\mathrm{p}=0.041, \mathrm{OR}=1.49$, 95\% CI 1.01-2.20 in co-dominant model 1 (C/C vs. C/T), and $\mathrm{p}=0.040, \mathrm{OR}=1.48,95 \% \mathrm{CI} 1.02-2.14$ in the dominant model $(\mathrm{C} / \mathrm{C}$ vs. $\mathrm{C} / \mathrm{T}$ and $\mathrm{T} / \mathrm{T}) ; \mathrm{rs} 231779, \mathrm{p}=0.005, \mathrm{OR}=1.64,95 \% \mathrm{CI}$ 1.16-2.30 in co-dominant model 1 ( $\mathrm{T} / \mathrm{T}$ vs. $\mathrm{T} / \mathrm{C}$ ), and $\mathrm{p}=0.009$, $\mathrm{OR}=1.54,95 \%$ CI 1.11-2.14 in the dominant model (T/T vs. $\mathrm{T} / \mathrm{C}$ and $\mathrm{C} / \mathrm{C}$ ), respectively] (Table III). However, there was no significant difference after Bonferroni correction. 
Table II. Allele frequencies of polymorphisms of CD28, CTLA4 and ICOS genes in NSV patients and control subjects.

\begin{tabular}{|c|c|c|c|c|c|c|}
\hline \multirow[t]{2}{*}{ Gene } & \multirow[t]{2}{*}{ SNP } & \multirow[t]{2}{*}{ Allele } & \multirow{2}{*}{$\frac{\mathrm{NSV}}{\mathrm{n}(\%)}$} & \multirow{2}{*}{$\frac{\text { Control }}{\mathrm{n}(\%)}$} & \multirow[t]{2}{*}{ OR $(95 \% \mathrm{CI})$} & \multirow[t]{2}{*}{$\mathrm{p}$-value } \\
\hline & & & & & & \\
\hline \multirow{8}{*}{$C D 28$} & rs1879877 & $\mathrm{A}$ & $280(60.6)$ & $491(61.4)$ & 1 & \\
\hline & -1198 & $\mathrm{C}$ & $182(39.4)$ & 309 (38.6) & $1.03(0.82-1.31)$ & 0.787 \\
\hline & rs3181097 & $\mathrm{A}$ & $235(50.9)$ & $403(50.0)$ & 1 & \\
\hline & -1059 & $\mathrm{G}$ & $227(49.1)$ & $403(50.0)$ & $0.97(0.77-1.21)$ & 0.767 \\
\hline & rs2140148 & $\mathrm{T}$ & $418(90.5)$ & $724(89.4)$ & 1 & \\
\hline & Intron 1 & G & $44 \quad(9.5)$ & $86(10.6)$ & $0.89(0.60-1.30)$ & 0.536 \\
\hline & rs3116494 & A & $431(93.3)$ & $743(91.7)$ & 1 & \\
\hline & Intron 2 & G & 31 (6.7) & $67 \quad(8.3)$ & $0.80(0.51-1.24)$ & 0.316 \\
\hline \multirow[t]{4}{*}{ CTLA4 } & rs231777 & $\mathrm{C}$ & $387(83.8)$ & $710(87.9)$ & 1 & \\
\hline & Intron 1 & $\mathrm{~T}$ & 75 (16.2) & $98(12.1)$ & $1.40(1.01-1.94)$ & 0.041 \\
\hline & rs231779 & $\mathrm{T}$ & $310(67.1)$ & $575(72.1)$ & 1 & \\
\hline & Intron 1 & $\mathrm{C}$ & $152(32.9)$ & $223(27.9)$ & $1.26(0.99-1.62)$ & 0.064 \\
\hline \multirow[t]{10}{*}{$I C O S$} & rs4270326 & $\mathrm{C}$ & $400(86.6)$ & $708(88.1)$ & 1 & \\
\hline & Intron 3 & $\mathrm{G}$ & $62(13.4)$ & $96(11.9)$ & $1.14(0.81-1.61)$ & 0.443 \\
\hline & rs11571314 & $\mathrm{A}$ & $382(82.7)$ & $674(84.3)$ & 1 & \\
\hline & Intron 3 & G & $80(17.3)$ & $126(15.8)$ & $1.12(0.82-1.52)$ & 0.469 \\
\hline & rs 10183087 & $\mathrm{~A}$ & $381(82.8)$ & $660(84.2)$ & 1 & \\
\hline & 3'UTR & $\mathrm{C}$ & 79 (17.2) & $124(15.8)$ & $1.10(0.81-1.50)$ & 0.532 \\
\hline & rs4404254 & $\mathrm{T}$ & $381(82.8)$ & $664(83.6)$ & 1 & \\
\hline & 3'UTR & $\mathrm{C}$ & 79 (17.2) & $130(16.4)$ & $1.06(0.78-1.44)$ & 0.714 \\
\hline & rs1559931 & $\mathrm{G}$ & $383(82.9)$ & $663(84.1)$ & 1 & \\
\hline & 3'UTR & A & $79(17.1)$ & 125 (15.9) & $1.10(0.80-1.49)$ & 0.568 \\
\hline
\end{tabular}

NSV, non-segmental vitiligo; CD28, CD28 molecule; CTLA4, cytotoxic T-lymphocyte-associated protein 4; ICOS, inducible T-cell costimulator; SNP, singe nucleotide polymorphism; UTR, untranslated region; OR, odds ratio; CI, confidence interval. n, number of subjects. p-values were calculated from logistic regression analyses. Bold numbers indicate significant associations.

Haploview 4.2 was used to evaluate LD and haplotypes among the polymorphisms of the CD28, CTLA4 and ICOS genes. Three LD blocks were observed among 11 SNPs of the CD28, CTLA4 and ICOS genes by the Gabriel method (data not shown). The haplotypes were constructed in block 1 of CD28, block 2 of CTLA4 and block 3 of ICOS. These haplotypes included the following SNPs: block 1 (rs1879877, rs3181097 and rs2140148); block 2 (rs231777 and rs231779); and block 3 rs4270326, rs11571314, rs10183087, rs4404254 and rs1559931). The haplotype (rs231777 and rs231779) of the CLTA4 gene displayed a difference between the NSV patients and the control subjects (TC, $\chi^{2}=4.069, \mathrm{p}=0.0437$; Table IV).

We also evaluated differences in three promoter SNPs according to clinical parameters of NSV. No significant differences were shown in allele, genotype or haplotype frequencies for polymorphisms based on the age of disease onset, a family history or co-existing autoimmune diseases.

\section{Discussion}

In the present study, we examined whether or not polymorphisms of the CD28, CTLA4 and ICOS genes are associated with patients with NSV. The causes of vitiligo remain under debate, but it is generally accepted to be an acquired disorder
(13). Genetic linkage and association studies have implicated a number of different susceptibility genes, such as glutathione S-transferase (GST), NLR family genes, pyrin domain containing 1 (NLRPl) and tyrosinase (TYR) (14-18). Liu et al reported that individuals in a sample of Chinese with mutant alleles of the GST gene were at high risk for vitiligo.

We also observed a significant association in null alleles of the GSTM1 gene $(\mathrm{p}<0.001, \mathrm{OR}=2.048,95 \%$ CI 1.529-2.743) in a previous study (14). Jin et al reported that a polymorphism of the NLRPI gene contributed to vitiligo susceptibility. In a genome-wide association study, a variant of the $T Y R$ gene was found to be associated with autoimmunity susceptibility in generalized vitiligo in a European population (15).

The CTLA4 polymorphisms previously investigated in autoimmune diseases include $+49 \mathrm{~A} / \mathrm{G}$ (rs231775) and microsatellite polymorphisms. A microsatellite polymorphism (106-bp) located in exon 3 of the CTLA4 gene is related to autoimmune diseases, such as Grave's disease (20). A SNP (rs231779) in intron 1 of CTLA4 was significantly associated with Grave's disease in a sample of Chinese Han individuals (16). The Thr17Ala polymorphism of CTLA4 was shown to be a genetic marker of autoimmune Addison's disease in a meta-analysis of European studies (17). An association between CTLA4 and vitiligo has been controversial. Several studies have also reported that 
Table III. Genotype frequencies of the polymorphisms of CD28, CTLA4 and ICOS genes in the NSV patients and control subjects.

\begin{tabular}{|c|c|c|c|c|c|c|c|}
\hline \multirow[t]{2}{*}{ Gene } & \multirow[t]{2}{*}{ SNP } & \multirow[t]{2}{*}{ Genotype } & NSV & Control & \multirow[t]{2}{*}{ Model } & \multirow[t]{2}{*}{ OR $(95 \%$ CI $)$} & \multirow[t]{2}{*}{ p-value } \\
\hline & & & $\mathrm{n}(\%)$ & $\mathrm{n}(\%)$ & & & \\
\hline \multirow[t]{16}{*}{$C D 28$} & rs 1879877 & $\mathrm{~A} / \mathrm{A}$ & $84(36.4)$ & $147(36.8)$ & Co-dominant1 & $1.00(0.70-1.42)$ & 0.978 \\
\hline & -1198 & $\mathrm{~A} / \mathrm{C}$ & $112(48.5)$ & $197(49.2)$ & Co-dominant 2 & $1.11(0.67-1.84)$ & 0.725 \\
\hline & & $\mathrm{C} / \mathrm{C}$ & $35(15.2)$ & $56(14.0)$ & Dominant & $1.02(0.73-1.43)$ & 0.910 \\
\hline & & & & & Recessive & $1.11(0.70-1.76)$ & 0.660 \\
\hline & rs3181097 & $\mathrm{A} / \mathrm{A}$ & $55(23.8)$ & $100(24.8)$ & Co-dominant1 & $1.13(0.76-1.68)$ & 0.577 \\
\hline & -1059 & $\mathrm{~A} / \mathrm{G}$ & $125(54.1)$ & $203(50.4)$ & Co-dominant 2 & $0.94(0.58-1.51)$ & 0.753 \\
\hline & & $\mathrm{G} / \mathrm{G}$ & $51(22.1)$ & $100(24.8)$ & Dominant & $1.07(0.73-1.56)$ & 0.740 \\
\hline & & & & & Recessive & $0.86(0.59-1.27)$ & 0.450 \\
\hline & rs2140148 & $\mathrm{T} / \mathrm{T}$ & $191(82.7)$ & $325(80.2)$ & Co-dominant1 & $0.83(0.54-1.28)$ & 0.396 \\
\hline & Intron 1 & $\mathrm{~T} / \mathrm{G}$ & $36(15.6)$ & $74(18.3)$ & Co-dominant2 & $1.14(0.32-4.11)$ & 0.847 \\
\hline & & $\mathrm{G} / \mathrm{G}$ & 4 (1.7) & $6(1.5)$ & Dominant & $0.85(0.56-1.30)$ & 0.450 \\
\hline & & & & & Recessive & $1.18(0.33-4.23)$ & 0.800 \\
\hline & rs3116494 & $\mathrm{A} / \mathrm{A}$ & $200(86.6)$ & $344(84.9)$ & Co-dominant1 & $0.97(0.60-1.56)$ & 0.898 \\
\hline & Intron 2 & $\mathrm{~A} / \mathrm{G}$ & $31(13.4)$ & $55(13.6)$ & Co-dominant 2 & $0.00(0.00-\mathrm{NA})$ & \\
\hline & & $\mathrm{G} / \mathrm{G}$ & $0 \quad(0.0)$ & $6(1.5)$ & Dominant & $0.87(0.55-1.40)$ & 0.570 \\
\hline & & & & & Recessive & $0.00(0.00-\mathrm{NA})$ & 0.020 \\
\hline \multirow[t]{8}{*}{ CTLA4 } & rs231777 & $\mathrm{C} / \mathrm{C}$ & $164(71.0)$ & $317(78.5)$ & Co-dominant 1 & $1.49(1.01-2.20)$ & 0.041 \\
\hline & Intron 1 & $\mathrm{~T} / \mathrm{C}$ & $59(25.5)$ & $76(18.8)$ & Co-dominant2 & $1.41(0.55-3.57)$ & 0.473 \\
\hline & & $\mathrm{T} / \mathrm{T}$ & $8(3.5)$ & $11 \quad(2.7)$ & Dominant & $1.48(1.02-2.14)$ & 0.040 \\
\hline & & & & & Recessive & $1.28(0.51-3.24)$ & 0.600 \\
\hline & rs231779 & $\mathrm{T} / \mathrm{T}$ & $98(42.4)$ & $212(53.1)$ & Co-dominant1 & $1.64(1.16-2.30)$ & 0.005 \\
\hline & Intron 1 & $\mathrm{~T} / \mathrm{C}$ & $114(49.4)$ & $151(37.8)$ & Co-dominant 2 & $1.15(0.62-2.10)$ & 0.668 \\
\hline & & $\mathrm{C} / \mathrm{C}$ & $19(8.2)$ & $36(9.0)$ & Dominant & $1.54(1.11-2.14)$ & 0.009 \\
\hline & & & & & Recessive & $0.91(0.51-1.62)$ & 0.740 \\
\hline \multirow[t]{20}{*}{ ICOS } & rs4270326 & $\mathrm{C} / \mathrm{C}$ & $174(75.3)$ & $312(77.6)$ & Co-dominant 1 & $1.11(0.75-1.64)$ & 0.602 \\
\hline & Intron 3 & $\mathrm{G} / \mathrm{C}$ & $52(22.5)$ & $84(20.9)$ & Co-dominant2 & $1.51(0.45-5.02)$ & 0.512 \\
\hline & & $\mathrm{G} / \mathrm{G}$ & $5(2.2)$ & $6(1.5)$ & Dominant & $1.14(0.78-1.66)$ & 0.510 \\
\hline & & & & & Recessive & $1.47(0.44-4.89)$ & 0.530 \\
\hline & rs11571314 & $\mathrm{A} / \mathrm{A}$ & $161(69.7)$ & $286(71.5)$ & Co-dominant 1 & $1.04(0.72-1.51)$ & 0.817 \\
\hline & Intron 3 & $\mathrm{~A} / \mathrm{G}$ & $60(26.0)$ & $102(25.5)$ & Co-dominant 2 & $1.48(0.63-3.51)$ & 0.372 \\
\hline & & $\mathrm{G} / \mathrm{G}$ & $10(4.3)$ & $12(3.0)$ & Dominant & $1.09(0.76-1.55)$ & 0.640 \\
\hline & & & & & Recessive & $1.47(0.62-3.45)$ & 0.390 \\
\hline & rs10183087 & $\mathrm{A} / \mathrm{A}$ & $161(70.0)$ & $280(71.4)$ & Co-dominant 1 & $1.02(0.70-1.49)$ & 0.893 \\
\hline & 3'UTR & $\mathrm{A} / \mathrm{C}$ & $59(25.6)$ & $100(25.5)$ & Co-dominant2 & $1.45(0.61-3.44)$ & 0.398 \\
\hline & & $\mathrm{C} / \mathrm{C}$ & $10(4.3)$ & $12(3.1)$ & Dominant & $1.07(0.75-1.53)$ & 0.710 \\
\hline & & & & & Recessive & $1.44(0.61-3.39)$ & 0.410 \\
\hline & rs4404254 & $\mathrm{T} / \mathrm{T}$ & $161(70.0)$ & $280(70.5)$ & Co-dominant 1 & $0.99(0.68-1.43)$ & 0.944 \\
\hline & 3'UTR & $\mathrm{T} / \mathrm{C}$ & $59(25.6)$ & $104(26.2)$ & Co-dominant 2 & $1.34(0.57-3.13)$ & 0.501 \\
\hline & & $\mathrm{C} / \mathrm{C}$ & $10 \quad(4.3)$ & $13(3.3)$ & Dominant & $1.02(0.72-1.46)$ & 0.890 \\
\hline & & & & & Recessive & $1.35(0.58-3.12)$ & 0.490 \\
\hline & rs 1559931 & $\mathrm{G} / \mathrm{G}$ & $162(70.1)$ & $280(71.1)$ & Co-dominant1 & $0.99(0.68-1.44)$ & 0.958 \\
\hline & 3'UTR & $\mathrm{A} / \mathrm{G}$ & $59(25.5)$ & $103(26.1)$ & Co-dominant 2 & $1.57(0.65-3.79)$ & 0.313 \\
\hline & & $\mathrm{A} / \mathrm{A}$ & $10 \quad(4.3)$ & $11(2.8)$ & Dominant & $1.04(0.73-1.49)$ & 0.810 \\
\hline & & & & & Recessive & $1.58(0.66-3.78)$ & 0.310 \\
\hline
\end{tabular}

NSV, non-segmental vitiligo; CD28, CD28 molecule; CTLA4, cytotoxic T-lymphocyte-associated protein 4; ICOS, inducible T-cell co-stimulator; SNP, singe nucleotide polymorphism; UTR, untranslated region; OR, odds ratio; CI, confidence interval; NA, not applicable. p-values were calculated from logistic regression analyses. Bold numbers indicate significant associations.

CTLA4 polymorphisms were associated with vitiligo $(18,19)$. For example, the GG genotype and $\mathrm{G}$ allele of the $+49 \mathrm{~A} / \mathrm{G}$ (rs231775) SNP of CTLA4 was observed at a higher frequency in vitiligo patients compared to control subjects (20). However, Deeba et al showed that there is no association between the CTLA-4 A49G gene polymorphism and vitiligo in a southern 
Table IV. Haplotype frequencies of polymorphisms of CD28,CTLA4 and ICOS genes in the NSV patients and control subjects.

\begin{tabular}{|c|c|c|c|c|c|c|c|}
\hline \multirow[t]{2}{*}{ Haplotype } & \multirow[t]{2}{*}{ Frequency } & \multicolumn{2}{|c|}{ NSV } & \multicolumn{2}{|c|}{ Control } & \multirow[t]{2}{*}{ Chi-square } & \multirow[t]{2}{*}{ p-value } \\
\hline & & + & - & + & - & & \\
\hline \multicolumn{8}{|l|}{ Block 1} \\
\hline AAT & 0.504 & 235 & 227 & 404 & 402 & 0.065 & 0.7988 \\
\hline CGT & 0.390 & 182 & 280 & 312 & 494 & 0.058 & 0.8089 \\
\hline AGG & 0.103 & 44 & 418 & 86 & 720 & 0.419 & 0.5173 \\
\hline \multicolumn{8}{|l|}{ Block 2} \\
\hline $\mathrm{CT}$ & 0.703 & 310 & 152 & 579.9 & 224.1 & 3.548 & 0.0596 \\
\hline $\mathrm{CC}$ & 0.160 & 77 & 385 & 126.1 & 677.9 & 0.210 & 0.6472 \\
\hline $\mathrm{TC}$ & 0.137 & 75 & 387 & 98.0 & 706.0 & 4.069 & 0.0437 \\
\hline \multicolumn{8}{|l|}{ Block 3} \\
\hline CAATG & 0.835 & 382 & 80 & 662 & 126 & 0.372 & 0.5419 \\
\hline GGCCA & 0.124 & 61 & 401 & 94 & 694 & 0.436 & 0.5093 \\
\hline CGCCA & 0.039 & 18 & 444 & 31 & 757 & 0.001 & 0.9734 \\
\hline
\end{tabular}

Haplotype of block 1 consists of rs1879877, rs3181097 and rs2140148. Haplotype of block 2 comprises of rs231777 and rs 231779 . Haplotype of block 3 consists of rs4270326, rs11571314, rs10183087, rs4404254 and rs1559931. NSV, non-segmental vitiligo. Bold number indicates significant associations.

Indian population (21). In the present study, CTLA4 SNPs (rs231777 and rs231779) were also shown to have no association with NSV. We also did not observe a significant association between NSV and the CD28 and ICOS genes.

We calculated the required sample size for sufficient statistical power using a genetic power calculator (http://pngu.mgh. harvard.edu/ purcell/gpc/cc2.html). In this study, the sample powers of our SNPs were 0.931 for rs $231777(\alpha=0.05$; genotype relative risk, 2-fold; number of cases for $80 \%$ power, 153 ) and 0.985 for $\mathrm{rs} 231779(\alpha=0.05$; genotype relative risk, 2 -fold; number of cases for $80 \%$ power, 105). Therefore, our results have statistical confidence.

In conclusion, we investigated whether SNPs of the $C D 28$, CTLA4 and ICOS genes are related to NSV in a sample of Korean individuals; we observed no significant associations between CD28, CTLA4 and ICOS and NSV in the Korean population.

\section{References}

1. Halder RM and Chappell JL: Vitiligo update. Semin Cutan Med Surg 28: 86-92, 2009.

2. Lafage-Pochitaloff M, Costello R, Couez D, et al: Human CD28 and CTLA-4 Ig superfamily genes are located on chromosome 2 at bands q33-q34. Immunogenetics 31: 198-201, 1990.

3. Lenschow DJ, Walunas TL and Bluestone JA: CD28/B7 system of T cell costimulation. Annu Rev Immunol 14: 233-258, 1996.

4. Magistrelli G, Jeannin P, Herbault N, et al: A soluble form of CTLA-4 generated by alternative splicing is expressed by nonstimulated human T cells. Eur J Immunol 29: 3596-3602, 1999.

5. Ihara K, Ahmed S, Nakao F, et al: Association studies of CTLA-4, CD28, and ICOS gene polymorphisms with type 1 diabetes in the Japanese population. Immunogenetics 53: 447-454, 2001.

6. Kristiansen OP, Larsen ZM and Pociot F: CTLA-4 in autoimmune diseases - a general susceptibility gene to autoimmunity? Genes Immun 1: 170-184, 2000.

7. Kim YO, Kim HJ, Kim SK, Chung JH and Hong SJ: Association of the CD28/CTLA4/ICOS polymorphisms with susceptibility to rheumatoid arthritis. Clin Chem Lab Med 48: 345-353, 2010.
8. Bouwhuis MG, Gast A, Figl A, et al: Polymorphisms in the CD28/ CTLA4/ICOS genes: role in malignant melanoma susceptibility and prognosis? Cancer Immunol Immunother 59: 303-312, 2010.

9. Gu LQ, Zhu W, Zhao SX, et al: Clinical associations of the genetic variants of CTLA-4, Tg, TSHR, PTPN22, PTPN12 and FCRL3 in patients with Graves' disease. Clin Endocrinol 72: 248-255, 2010.

10. Gabriel SB, Schaffner SF, Nguyen H, et al: The structure of haplotype blocks in the human genome. Science 296: 2225-2229, 2002.

11. Jung KH, Ban JY, Kim HJ, et al: Genetic association study of THRB polymorphisms with obesity in Korean population. Mol Cell Toxicol 4: 124-131, 2008.

12. Han DH, Kim SK, Kang SW, et al: Matrix metallopeptidase 2 gene polymorphism is associated with obesity in Korean population. Korean J Physiol Pharmacol 12: 125-129, 2008.

13. Boissy RE and Spritz RA: Frontiers and controversies in the pathobiology of vitiligo: separating the wheat from the chaff. Exp Dermatol 18: 583-585, 2009.

14. Uhm YK, Yoon SH, Kang IJ, et al: Association of glutathione S-transferase gene polymorphisms (GSTM1 and GSTT1) of vitiligo in Korean population. Life Sci 81: 223-227, 2007.

15. Jin Y, Birlea SA, Fain PR, et al: Variant of TYR and autoimmunity susceptibility loci in generalized vitiligo. N Engl J Med 362: 1686-1697, 2010.

16. Zhao SX, Pan CM, Cao HM, et al: Association of the CTLA4 gene with Graves' disease in the Chinese Han population. PLoS One 5: e9821, 2010.

17. Brozzetti A, Marzotti S, Tortoioli C, et al: Cytotoxic T lymphocyte antigen-4 Ala17 polymorphism is a genetic marker of autoimmune adrenal insufficiency: Italian association study and meta-analysis of European studies. Eur J Endocrinol 162: 361-369, 2010

18. Birlea SA, Laberge GS, Procopciuc LM, Fain PR and Spritz RA: CTLA4 and generalized vitiligo: two genetic association studies and a meta-analysis of published data. Pigment Cell Melanoma Res 22: 230-234, 2009.

19. Blomhoff A, Kemp EH, Gawkrodger DJ, et al: CTLA4 polymorphisms are associated with vitiligo, in patients with concomitant autoimmune diseases. Pigment Cell Res 18: 55-58, 2005.

20. Pehlivan S, Ozkinay F, Alper S, et al: Association between IL4 (-590), ACE (I)/(D), CCR5 (Delta32), CTLA4 (+49) and IL1-RN (VNTR in intron 2) gene polymorphisms and vitiligo. Eur J Dermatol 19: 126-128, 2009.

21. Deeba F, Syed R, Quareen J, et al: CTLA-4 A49G gene polymorphism is not associated with vitiligo in South Indian population. Indian J Dermatol 55: 29-32, 2010. 